\title{
Cuerpo, poder y resistencia (Para el archivo de las actuales políticas de control social)
}

\author{
Iván Pincheira Torres ${ }^{1}$
}

\begin{abstract}
Resumen
El artículo plantea que los cuerpos humanos, en tanto objetos concretos, están sometidos a las condiciones de un contexto determinado, por lo tanto funcionan bajo condiciones de ese tiempo y espacio en particular. En estas condiciones del contexto surgen también determinadas formas sociales y políticas de ejercer poder y control sobre dichos cuerpos.
\end{abstract}

Palabras clave: Cuerpo, Poder, Política, Biopolítica, Resistencia.

\begin{abstract}
The article suggests that human bodies, while specific objects are subject to the conditions of a particular context, therefore operate under conditions of that time and space in particular. Under these conditions arise context also certain social and political forms of exercising power and control over such bodies.
\end{abstract}

Key words: Body, Power, Politics, Biopolitics, Resistance.

1 Sociólogo. Universidad de Concepción. Magíster Estudios Latinoamericanos, Universidad de Chile. Dr. (c) en Estudios Latinoamericanos USACH. 
Cuerpo, poder y resistencia. (Para el archivo de las actuales políticas de control social) Iván Pincheira Torres

¿Por qué ocuparnos de la cuestión del cuerpo, de los cuerpos, cuando, en apariencia, aparece como una dimensión ajena a lo social? Creo que la respuesta podría ir en el sentido de comprender que los cuerpos no existen de forma abstracta sino concreta, y por lo tanto sólo funcionan bajo determinadas condiciones, situadas en un tiempo y un espacio dado. Es decir, que podemos inscribir el desenvolvimiento de los cuerpos al interior de un conjunto de relaciones que lo articulan con un orden social determinado. Es dentro de este orden social determinado que el concepto de políticas del cuerpo o control social del cuerpo aparece a la base.

\section{Cartografías del cuerpo}

A partir de lo anterior, y siguiendo a Bryan Turner, constataremos que, aunque siempre presente en el imaginario cristiano-occidental, su rol en la constitución de lo social ha sido relegado. Por tanto éste, el cuerpo, aparece vinculado a un supuesto estado de naturaleza que aparece como dicotómico frente a la necesidad de estructurar lo social en base a los valores de la razón. Será, en versión de Turner, gracias a las teorías feministas que el cuerpo vuelve a reposicionarse y a entenderse ya no como algo dado e inmutable, sino que construido y conflictuado en el contexto de las relaciones sociales. "La teoría feminista ha sometido a un examen crítico la noción de que la biología es igual a destino. La diferenciación fisiológica de cuerpos femeninos y masculinos no corresponde más a ninguna división social y moral importante. ${ }^{2}$ Es de este modo que los feminismos anuncian que el cuerpo de mujer no podía seguir estando prisionero de esencialismos que, al ubicarlo en el lugar de la naturaleza, garantizaban el estatuto de subordinación de las mujeres.

El cuerpo no es un puro dato de la biología, sino que un punto de anclaje de las más variadas representaciones. Representaciones, las cuales, continuamente lo van reconstituyendo, rehaciendo y deshaciendo. Es de esta manera que, a continuación,

2 Turner, Bryan (1989). El cuerpo y la sociedad. Exploraciones en teoría social. Pág. 17. 
Thomas Laqueur ${ }^{3}$ va a venir a plantear que el conocimiento de nuestro cuerpo, de nuestra sexualidad, ha ido cambiando a través del tiempo de Occidente; pasando de un modelo (que va desde la medicina griega hasta bien entrado el siglo XVII) que concebía que tanto hombres y mujeres tenían un mismo sexo, a un modelo de distinción sexual, en donde hombres y mujeres aparecen portadores de sexualidades diferenciadas. En este sentido, el sexo, el cuerpo, es una construcción social.

Lo que entendemos por sexualidad, por corporalidad, es una construcción discursiva propia de cada época. Es esto lo que a lo largo de "La construcción del sexo" Thomas Laqueur busca demostrar, de cómo la ruptura del modelo de un sexo y el establecimiento de los dos sexos no fue consecuencia del cambio científico sino más bien de una revolución epistemológica y político-social, en donde distintas luchas y situaciones retóricas concretas hicieron que hombres y mujeres hablaran como si ya hubiera dos sexos.

El cuerpo es naturaleza mediada por el efecto de prácticas culturales, históricas y sociales; será en ese sentido que David Le Breton, reclama el derecho a existencia de una Sociología del Cuerpo, cuyo campo de estudio sea la corporeidad humana como fenómeno social y cultural, materia simbólica, objeto de representaciones y de imaginarios. De modo que el cuerpo estaría constantemente moldeado por el contexto social y cultural en que se sumerge el actor. "Lo que el hombre pone en juego en el terreno de lo físico se origina en un conjunto de sistemas simbólicos. Del cuerpo nacen y se propagan las significaciones que constituyen la base de la existencia individual y colectiva". ${ }^{4}$ El cuerpo, así, no existe en estado natural, siempre está inserto en la trama del sentido.

3 Laqueur, Thomas (1994). La construcción del sexo.

4 Le Breton, David (2002). La Sociología del Cuerpo. Pág. 7. 


\section{Para el registro de las distintas formas de control social del cuerpo}

Realizada esta mirada al campo de estudio que se despliega en torno a la cuestión del cuerpo, en lo que viene a continuación nos concentraremos en el concepto de poder, por cuanto si de las lecturas anteriores podemos desprender que las constituciones corpóreas se inscriben al interior del amplio campo de las relaciones sociales, debemos asumir que ese amplio campo de las relaciones sociales está continuamente atravesado por relaciones de poder.

Serán estas relaciones de poder inscritas sobre los cuerpos las que debemos entenderlas como inscripciones propias de momentos históricos determinados, lo que nos indica distintas formas en esta relación. A distintos modos de producción, a distintas necesidades, a diferentes funcionalidades, distinto tratamiento del cuerpo. De esta forma, nos hemos introducido en la problemática del gobierno de los cuerpos, de las técnicas y las tecnologías necesarias que para ello históricamente se han implementado.

Ahora bien, un registro de este tipo no debe aparecer como un esquema rígido de las distintas etapas por las cuales han atravesado, lo que hemos venido en denominar las políticas del cuerpo. Por cuanto se asume que las prácticas de poder que se ejecutan sobre los cuerpos están siempre transitando, siempre apareciendo, siempre re-editándose. Sin embargo, y en función de cuáles sean los rendimientos esperados, se puede sostener que unas u otras prácticas tienen mayor o menor relevancia según sea el periodo histórico en el que nos situemos.

Es de esta manera que, en un primer momento, nos encontramos en presencia de un sobre/poder que se inscribe en los cuerpos a través del castigo y suplicio. Aquí estamos en presencia de un poder que no sólo no disimula que se ejerce directamente sobre los cuerpos, sino que se exalta y se refuerza con sus manifestaciones físicas, de un poder que cobra nuevo vigor al 
hacer que se manifieste ritualmente su realidad de sobrepoder. Es esta manifestación no mediada entre poder y cuerpo, la que podemos encontrar desplegada en el periodo que corresponde al de la instalación del dominio europeo-occidental en territorio americano.

En este periodo el espectáculo y la teatralización del suplicio y el sacrificio poseen un carácter constitutivo en la empresa de conquista española. Los cuales van a venir a desempeñar el lugar ceremonial de la fuerza desmesurada, desmedida y grotesca que afianza la posición de poder y dominio del conquistador. "Su objeto es menos restablecer un equilibrio que poner en juego, hasta su punto extremo, la disimetría entre el súbdito que ha osado violar la ley, y el soberano omnipotente que ejerce su fuerza ... la ejecución de la pena no se realiza para dar el espectáculo de la mesura, sino el del desequilibrio y del exceso."

Pero esta imposición del suplicio y el castigo a la vez que se traslada de escenario (el nuestro no es el escenario europeo que describe Foucault), también trasladará sus objetivos; ya no buscará tan sólo la subordinación de los súbditos a través de la escenificación periódica del castigo, sino que busca asegurar, mediante la rutinización del suplicio y el castigo, el dominio sobre los territorios y sobre los indios, y sobre los aborígenes, y sobre los naturales, y sobre los primitivos.

Posteriormente, en un segundo momento, damos cuenta de la aparición de toda una red institucional destinada ya no al castigo, sino que a la corrección de los cuerpos; a este segundo momento se le ha venido en llamar sociedad disciplinaria. La sociedad disciplinaria es aquella en la que la dominación social se construye a través de una red difusa de dispositivos y aparatos que producen y regulan las costumbres, los hábitos y las prácticas productivas. Aquí el cuerpo adquiere una significación totalmente diferente y deja de ser aquello que debe ser atormentado para convertirse en

5 Foucault, Michel. Vigilar y Castigar. Pág. 54. 
Cuerpo, poder y resistencia. (Para el archivo de las actuales políticas de control social) Iván Pincheira Torres

algo que ha de ser formado, reformado, corregido, en un cuerpo que debe adquirir aptitudes, recibir ciertas cualidades.

Estamos refiriéndonos a la relación que se establece entre el cuerpo y el capitalismo; aquí el cuerpo se ha mercantilizado, convirtiéndose en fuerza de trabajo. Es en este periodo que asistimos a la vigilancia ininterrumpida del panoptismo, en donde surgen las "instituciones unitarias de secuestro de los cuerpos, de enclaustramiento, tales como la fábrica, la prisión, la escuela, el hospital, el psiquiátrico, los reformatorios, el hospicio, los cuarteles, etc., donde se encuentran espacialmente concentradas las distintas tecnologías de fabricación de cuerpos" ${ }^{\prime \prime}$.

La emergencia de la sociedad disciplinaria en Latinoamérica la podemos rastrear hacia el periodo post-independentista. De modo que después de la primera fase de la conquista, efectuada por la corona española, viene una segunda fase, que corresponde precisamente al periodo descrito aquí. Durante esta fase, las clases dominantes deben disciplinar a una mano de obra indígena y mestiza. En ausencia de industrialización y de grandes actividades comerciales, es la minería la que, en un primer momento, se transformará en el terreno ideal donde el capitalismo chileno tratará de disciplinar a su mano de obra.

Para María Angélica Illanes ${ }^{7}$, la proletarización y sobre todo la acumulación capitalista pasarán por una serie de medidas de orden económico (legislación sobre la propiedad, sanciones a deudores, etc.), de control social (restricciones al libre movimiento de peones, eliminación de barrios pobres, etc.), de tipo ideológico (prohibición de ciertos tipos de fiestas y juegos populares) y jurídico-policiales (reintroducción del castigo de azotes, multas, etc.). Todas éstas, medidas que constantemente serán renovadas y redituadas a lo largo del siglo XX.

6 Nievas, Flavian (1999). El control social de los cuerpos. Pág. 81.

7 Illanes, María Angélica (2003). Chile Des-centrado. Formación socio-cultural republicana y transición capitalista (1810-1910). 
En un tercer momento nos vamos a hallar con que en función de las transformaciones de la sociedad en general en este último siglo, se estarían engendrando formas de control social distintas a las disciplinarias, las que aún subsistirían pero que ya no explican la totalidad de la normalización ni el control. Estamos hablando de la sociedad del control.

Es Gilles Deleuze ${ }^{8}$ quien plantea esta transmutación, en tanto crisis de las instituciones de encierro. Pero esto no significa que hayan desaparecido, sino que operan en otro nivel. Ya no es necesario el visible y tosco encierro con muros de cemento; los nuevos encierros son sociales.

En el actual periodo de la instalación del mercado mundial se ha pasado de la producción industrial como eje vertebrador a la prioridad de la producción de la propia vida social, a la producción biopolítica, donde se mezcla lo económico, lo político y lo cultural, sin poderse aislar esas esferas entre sí. Es de esta forma que se nos aparece el nuevo modelo de la sociedad de control, de aquí en adelante los mecanismos de dominio se distribuyen directamente por los cerebros y los cuerpos de los ciudadanos. En este nuevo modelo societario, dicen Hardt y Negri, "... el poder se ejerce a través de maquinarias que organizan directamente los cerebros (en el sistema de comunicación, las redes de información, etcétera) y los cuerpos (en el sistema de asistencia social, las actividades controladas) con el propósito de llevarlos hacia un estado autónomo de alienación."

Para caracterizar de mejor forma a la nueva sociedad del control, estos autores recogen el concepto foucaultiano de biopoder. Este concepto dice relación con una forma de poder que regula la vida social desde su interior mismo. De lo que se trataría es de la vigilancia, control, represión ininterrumpida de la vida, sin necesidad de ocupar los antiguos espacios de encierro.

\footnotetext{
8 Deleuze, Gilles (1993). “El marketing es el nuevo control social”. Página 12, 26/6/93. En Flavian Nievas. Op. Cit.

9 Hardt, Michael; Negri, Antonio. Imperio. Pag. 38.
} 
Cuerpo, poder y resistencia. (Para el archivo de las actuales políticas de control social) Iván Pincheira Torres

Es así como se establece una relación no mediada, directa; es el cara a cara entre el poder y el cuerpo. Para graficar esta relación Gilles Deleuze propuso en su artículo de $1993^{10}$ al marketing como modelo del nuevo control social por excelencia. El marketing es una forma de localización rápida: organiza y discrimina en forma permanente en función del consumo, produciendo una malla continua y flexible de control, contraria al modo estático de las redes institucionales de la sociedad disciplinaria. El hombre ya no es el hombre encerrado, sino el hombre endeudado.

En definitiva, en el paso de la sociedad disciplinaria a la sociedad de control, se logran establecer relaciones de dominación en la totalidad de las relaciones sociales, objetivo que el capitalismo había perseguido a lo largo de todo su desarrollo. Y es en este sentido que surge la necesidad de abrir el archivo de los actuales mecanismos de control social, como una posibilidad cierta de descripción del presente. Ahora es el momento de ahondar en la especificidad del archivo, de modo que podemos plantear que uno de los ejes centrales de este archivo será el tratamiento que se ha hecho del concepto del miedo; el miedo como eje articulador de los actuales mecanismos de control social; el miedo como esa manera (perversa manera) en que el poder regula la vida social desde su interior mismo.

\section{Las políticas del miedo en el Chile de la post- dictadura}

«Los gobiernos del mundo están siguiendo una nueva y peligrosa agenda en la que se utiliza el lenguaje de la libertad y la justicia para aplicar políticas de miedo e inseguridad». Amnistía Internacional, informe anual 2005.

La modernidad se funda en la idea de que los descubrimientos técnico-científicos, el desarrollo de la sociedad industrial y la instalación del Estado-nación asegurarían el progreso y desen-

10 Deleuze, Gilles (1993). “El marketing es el nuevo control social”. Op. Cit. 
volvimiento al infinito de la humanidad. Sin embargo, a la hora del recuento nos encontramos con el surgimiento de un escenario saturado de miedos e inseguridades que ponen en tensión las modernas instituciones de la sociedad. "Sociedad del riesgo", diría el alemán Ulrich Beck.

Ahora bien, si la puesta en entredicho de los soportes mismos del proyecto modernizador se evidencia a partir de la generalización del riesgo, la inseguridad y el miedo; a continuación vamos a plantear que será sobre ese mismo flujo del temor que se inscriben las nuevas prácticas de control social. Es así como aparecen los dispositivos del miedo a la base de los actuales mecanismos de control social.

No es que el miedo no haya sido utilizado anteriormente como dispositivo de control social, si ya sabemos que en todo juego de poder el echar mano al recurso del miedo está siempre presente. Sin embargo, el carácter que hoy día adquiere la figura del miedo la hace aparecer como un fenómeno totalmente distinto de versiones anteriores.

\section{Biopolítica}

Si en la ciudad medieval amurallada el peligro se encontraba extramuros, en las ciudades modernas lo peligroso se halla en la propia urbe. Será en este sentido que Michel Foucault plantea que desde fines del siglo XVII aparece una tecnología disciplinaria, mientras que hacia la segunda mitad del siglo XVIII aparece la biopolítica ${ }^{11}$.

Lo que habría formado los primeros objetos de saber y los primeros objetivos de control del biopoder fueron los procesos de conjunto específicos de la vida (proporción de nacimientos y decesos, producción, enfermedad) que, en la segunda mitad del siglo XVIII estaban en conexión con todo un conjunto de pro-

11 Foucault, Michel (1976). Undécima Lección en el College de France. Del poder de soberanía al poder sobre la vida. Ver en la web en: http:/ / foucault.pais-global.com.ar/ 
Cuerpo, poder y resistencia. (Para el archivo de las actuales políticas de control social) Iván Pincheira Torres

blemas económicos y políticos. Es de este modo que cuando el Estado moderno alcanzó su forma más acabada, la vigilancia y la disciplina fueron reforzadas por un control político de la vida social de los individuos, que es lo que se denomina Biopoder.

En esta misma línea de pensamiento se hace pertinente revisar la propuesta de Giorgio Agamben. En versión de éste, la distinción entre la vida y la política que los antiguos establecían entre zoé y bios, entre vida biológica y vida política, habría desaparecido. Sería, entonces, esta imbricación directa entre vida biológica y la vida política lo que constituye el acontecimiento decisivo de la modernidad y el soporte sobre el cual se montan los actuales dispositivos de la biopolítica.

En concordancia con lo anterior, es que Agamben nos propone la extensión permanente del Estado de excepción $n^{12}$. El poder soberano, que se desentiende del orden jurídico, y sus subordinados, que son despojados de sus derechos para que éste (el soberano) disponga de sus vidas bajo la lógica de la excepción, se ha transformado en regla. La excepción se habría transformado en un estado permanente. De este modo, la política occidental crea un nuevo tipo de vida. Agamben la llama nuda vida..$^{13}$

La nuda vida, o vida desnuda, es la existencia despojada de todo valor político o de todo sentido ciudadano. El campo de concentración es el espacio más radical, donde se ejecutan las biopolíticas contemporáneas: donde la vida, privada de todo derecho, puede ser objeto de todos los experimentos.

La política actual está plagada de ejemplos de campos de concentración: las prisiones de Bush, los aeropuertos, las zonas fronterizas entre los países, los campos de refugiados, los centros de detenciones para inmigrantes ilegales, qué decir de los cen-

12 Agamben, Giorgio (2000). Estado de Excepción. Homo Sacer II. Adriana Hidalgo Editora.

13 Agamben, Giorgio (2002) Lo que queda de Auschwitz. El archivo y el testigo. Homo Sacer III, Pre-Textos. 
tros de tortura del periodo dictatorial. En todos estos espacios los sujetos están despojados de sus derechos por parte de un poder soberano, que tiene decisión absoluta sobre sus vidas.

El Estado de excepción se transforma en regla en tanto se instalan como espacios permanentes de excepción. Pero a pesar de todo, se nos aparecen como lugares distantes; Guantámo es un pretérito y lejano lugar, donde se encarcelan pretéritas y lejanas gentes, enroladas en pretéritas y lejanas guerras.

Sin embargo, la cuestión se nos aparece más cercana desde el momento en que entendemos que la existencia permanente de la excepción, justificada ya sea por razones de seguridad, en nombre del bien común o en contra de los ejes del mal, ha hecho del ser humano un sospechoso por excelencia, y como dice Agamben: "al punto de haber transformado en clase peligrosa a la humanidad misma". Estado de excepción, por lo tanto, no sólo permanente, sino que extendido y ramificado por los ganglios de lo social.

\section{Miedo}

Luego de esta revisión al concepto de biopolítica, podemos constatar cómo en nuestra contemporaneidad se logran establecer relaciones de dominación en la totalidad de las relaciones sociales, objetivo que el capitalismo había perseguido a lo largo de todo su desarrollo. Es en este sentido que surge la necesidad de abrir el archivo de los actuales mecanismos de control social. De este modo nos encontramos con que las políticas del miedo aparecen como la forma predominante; el miedo como esa manera (perversa manera) en que el poder regula la vida social desde su interior mismo.

¿Qué tienen en común la batalla contra una nueva epidemia, el fortalecimiento de las barreras frente a la inmigración clandestina, la guerra contra el terrorismo, las estrategias utilizadas para 
Cuerpo, poder y resistencia. (Para el archivo de las actuales políticas de control social) Iván Pincheira Torres

neutralizar el último virus informático? Para Roberto Esposito ${ }^{14}$ lo que es común a estas situaciones, supuestamente dispares, es la búsqueda de la inmunización: el paradigma que por excelencia describiría los actuales mecanismos de control social. Frente al miedo de un contagio planetario (de cualquier género), la exigencia parece ser la de una "guerra preventiva", que aniquile el síndrome aun antes de que pueda cosechar sus víctimas. Adquirir inmunidad respecto a todo lo que puede trastrocar los hábitos de vida, las lógicas políticas, las prácticas sociales y económicas, es el sueño occidental contemporáneo.

\section{El miedo y la prevención a la base de las políticas de inmunización que describe Esposito.}

El miedo y la prevención a la base de las políticas de control social del Chile de la post-dictadura. En nuestra contemporaneidad el temor y la prevención se expanden por las calles de la inseguridad. Es la imagen de un delincuente omnipotente y omnipresente la que condensa un temor generalizado y, por lo mismo, exagerado. Es sobre el miedo al otro que se estructura un nuevo tipo sociabilidad. Será el Programa de Naciones Unidas para el Desarrollo, en su informe para Chile del 1998, quien plantea que: "La transición está acompañada de un temor difuso que, a falta de amenaza explícita, se cristaliza nuevamente en la delincuencia. A partir de 1990 se afianza la percepción de que la delincuencia ha crecido y que está fuera de control". ${ }^{15}$

En el Chile de la post-dictadura, se ha pasado de las doctrinas de la seguridad nacional a las doctrinas de la seguridad ciudadana, como nuevo dispositivo discursivo que legitime los actuales mecanismos de control social. En nuestras ciudades pánico, como las denomina el italiano Paul Virilio, se nos anuncia

14 Esposito, Roberto (2005). Immunitas. Protección y negación de la vida. Amorrortu Editores.

15 Programa de Naciones Unidas para el Desarrollo (1998). Informe de Desarrollo Humano en Chile: las paradojas de la modernización. PNUD. Santiago. 
más criminalidad que las criminalidades realmente existentes. Surge así un sentimiento colectivo, cristalizado en terror, el cual se convierte en un movilizador de tolerancias cero a cargo de las mismas manos duras que anuncian más criminalidades que las criminalidades realmente existentes.

Este será el tono desde el cual los periodistas Marcela Ramos y Juan Andrés Guzmán intentan abordan este tema. En La guerra y la paz ciudadana ${ }^{16}$, un texto que analiza los discursos de la prensa chilena de los noventa y los ejes doctrinarios de la fundación Paz Ciudadana, estos autores proponen entender la problemática de la seguridad ciudadana como un corpus doctrinario polarizador del entorno social. Esta concepción de la seguridad ciudadana presenta también un componente de control social muy poderoso, y que a la larga, constituiría una suerte de paradigma donde el "miedo al otro" se erige como principio rector de las interacciones sociales.

Es así como, a partir de algunos casos paradigmáticos, distintos medios de comunicación introducen el problema de la seguridad ciudadana como la preocupación pública principal. No obstante, la percepción generalizada del aumento de la violencia criminal no tiene un correlato en las estadísticas de criminalidad. Así se revela que: "Durante los '90, la tasa de homicidios cayó en forma constante hasta acumular una baja de 50 por ciento al entrar al 2000, entonces, morir en un asalto se hizo casi tan difícil como hacerse millonario en los juegos de azar."17

A estas horas de la locura se nos aparecen evidentes las consecuencias nefastas de la inclusión del miedo en las agendas del poder. Es Norbert Lechner quien sostenía que los miedos son fuerzas peligrosas, las cuales pueden producir parálisis, pueden inducir al sometimiento y ser presa fácil de manipulación. Sin embargo, si aceptamos que el miedo se encuentra al centro de los

16 La guerra y la paz ciudadana (2000). M. Ramos. Juan A. Guzmán. Lom Ediciones. 17 Ídem, pág. 46. 
Cuerpo, poder y resistencia. (Para el archivo de las actuales políticas de control social) Iván Pincheira Torres

juegos de poder, debemos aceptar del mismo modo que el poder siempre se ejerce en condiciones de resistencia y subversión. $Y$ será acerca de estas posibilidades que nos concentraremos a continuación.

\section{Los procesos de resistencia en la post-dictadura}

Una cuestión que se nos podría objetar es el aparente carácter unidimensional con que se ha descrito el proceso de control social. Como si sólo existiera la acción sin contrapeso de un sobrepoder. Pero eso no es así, el poder siempre se ejerce en condiciones de resistencia y negación. Porque sólo inscribiendo el análisis en estas coordenadas podemos entender esta búsqueda casi delirante por perfeccionar los mecanismos de dominación, los cuales continuamente son sobrepasados por los sujetos a los cuales se busca sujetar. De modo que el capitalismo tiene el imperativo, antes de producir cosas, de producir sujetos. Que logre o no producirlos a la exacta medida de sus requerimientos es justamente lo que configura las luchas sociales contemporáneas.

En medio del más absoluto de los naufragios, en los tiempos en que el poder sin ningún tipo de mediación ha cercado la vida por los cuatro costados, el panorama no parece muy alentador. Sin embargo, dejadme plantear una sola posibilidad dentro de la imposibilidad. Una posibilidad que más bien parece una tonalidad que se acopla al ritmo cadencioso de los procesos de empoderamiento que se gestan y cuajan en el resto de Latinoamérica.

Válidas son todas las reservas respecto a las reales posibilidades de los movimientos sociales que han irrumpido en el escenario de Latinoamérica, válidos son los temores de quienes avizoran que al final de todos estos procesos se encuentra el Banco Mundial, la Organización Mundial de Comercio, siempre atenta a cobrar la vetusta deuda e imponer políticas económicas.

Pero ni todas las distantes y cómodas reservas respecto del proceso latinoamericano, ni los anestesiantes e inhibidores temo- 
res, pueden desconocer la existencia y levantamiento de distintas experiencias que han venido a poner en cuestión la hegemonía del comando neoliberal.

Sin abandonar el cadencioso ritmo que se impone en Latinoamérica, sostendremos que la verdad ya no debe ser entendida como develamiento, algo que está escondido y que debe ser descubierto. No, a la verdad no se llega, la verdad se construye. No se puede acceder a la realidad del ser, dice Nietzsche, sólo podemos acceder a la realidad del ser que nosotros hemos construido. Si vamos a asumir la verdad como construida, también debemos asumir que esta constitución de verdad se inscribe al interior de juegos de poder.

La verdad como construcción, la verdad como espacio de disputa. La vieja disquisición gramsciana acerca de los bloques hegemónicos hoy vuelve a redituarse, pero esta vez el escenario es distinto. La nuestra es la escena en que la hegemonía del poder ha invadido todos los territorios del cuerpo social e individual. Por lo tanto, lo que está en disputa es la vida en su integralidad. Y cuando es la vida en su integralidad que se encuentra controlada, será la vida misma la que busca liberarse.

Es así como las nuevas luchas sociales que vemos emerger rebasan el campo de la pura conciencia, para plantearse como luchas ético/estéticas; éticas en tanto son formas de ser en el mundo las que se ponen en juego, siendo el devenir cotidiano el lugar de disputa y de empoderamiento, las cuales no apuntan necesariamente a confluir hacia el espacio institucional de la soberanía estatal, como tampoco se convocan desde los discursos que pretenden modelos de sociedad totalizantes ${ }^{18}$.

18 Se podría sostener que habrían dos momentos en que los feminismos aparecen como fundantes de este desplazamiento hacia las luchas ético/políticas. El primero se vincula a la instalación en el debate de "Lo privado es político" y "Democracia en el Estado y en el hogar". A partir de estos enunciados, que buscando materialización en el espesor de lo real, o al menos encriptándose en la memoria colectiva, se anota claramente esta vocación por la cotidianidad de la lucha política. El segundo momento nos refiere la cuestión de los métodos anticonceptivos. Es así que en las luchas por la masificación de 
Cuerpo, poder y resistencia. (Para el archivo de las actuales políticas de control social) Iván Pincheira Torres

Pero estas luchas también son estético/políticas, en tanto no son sólo estados de conciencia (falsa o verdadera conciencia, según el marxismo clásico) los que están puestos en juego, sino que, desde el instante que es el devenir cotidiano el lugar de disputa y de empoderamiento, no el puro enunciado, la pura consigna, la pura concientización de la masa lo que emerge en estas luchas micropolíticas, sino que será la corporalidad misma y sus puestas en escena lo que efectivamente se pone en juego.

La modernidad, de la cual los Estados-nación latinoamericanos (y las sociabilidades impuestas por éstos) son herederos directos, le otorga un status privilegiado a la mente como la definición de la persona. En el pienso luego existo, de Descartes, se le otorga un status desvalido al cuerpo, a favor de la conciencia. Pues bien, las luchas contemporáneas abren la posibilidad de negar cualquier posición central a la subjetividad (el sujeto pensante cartesiano/moderno) y tomar al cuerpo, y sus formas de aparecimiento, como espacio de disputa y empoderamiento. Es así como en el actual ciclo de la luchas sociales, los aparecimientos, las formas, las imágenes, las puestas en escena, las intervenciones sobre el cuerpo/piel, las perfomances callejeras de las tribus urbanas, aparecen a todas luces, como siendo parte de un conjunto de prácticas estético/políticas. ${ }^{19}$

la anticoncepción, podemos leer cómo, en la cuestión de la reproducción y el manejo de la propia sexualidad, existe una opción ética/política desde el momento que son quienes comparten la cotidianidad del yo quienes deciden sobre la propia sexualidad. Decisión ética/política que se transforma en lugar de disputa y de empoderamiento; disputa desde el momento que enfrenta a los espacios oficiales que pretenden direccionar la sexualidad; empoderamiento desde el momento en que me doto de la capacidad de optar entre qué hacer y qué no hacer con ella.

19 Será nuevamente a partir de la erupción de los feminismos que se revela la importancia del cuerpo y la necesidad de re-ubicarlo al interior de relaciones sociales. Como ya lo expusimos al principio de este artículo, el cuerpo, especialmente el cuerpo de mujer, ya no se nos aparece como un compuesto orgánico que se desarrolla con independencia de los avatares de lo social. Por el contrario, el cuerpo es el lugar de enquistación de significaciones, interpretaciones, juegos de poder que lo entienden y lo ubican en distintas posiciones de subordinación. El cuerpo al ser inscrito en lo social (y siendo tensionado por las relaciones de poder que cruzan a éste) aparece como campo de disputa y de empoderamiento; disputa en tanto debe enfrentarse a las ideologías, técnicas y tecnologías que intentan disciplinarlo para normalizarlo y hacerlo productivo; campo de empoderamiento en tanto territorio 
Es así como las nuevas luchas sociales rebasan el campo de la pura conciencia, para plantearse como luchas ético/estéticas, las cuales parecen insistir en aquel aspecto que dice relación con una politización de la vida cotidiana y del ámbito privado, con el intento de desarrollar formas alternativas de convivencia, producción y consumo, transformando en el proceso a los hombres y mujeres concretas que componen la sociedad. Es en este sentido que su propuesta parece tener que ver con nuevos modos de seren el-mundo-individuales, a la manera de constitución de nuevas subjetivaciones y nuevos modos de estar-en-el-mundo-colectivo, a la manera de constitución de nuevas sociabilidades.

Será, entonces, el diálogo y el fortalecimiento de estas experiencias que están repoblando lo social, la urgente tarea que se le impone a la nueva intelectualidad que está repoblando la academia. El mantenerse al margen de estos procesos de re-significación y renovación de la vida, que representan las nuevas propuestas de acción colectiva, sólo significará el enclaustramiento marginal de una academia que se pretende descriptora y partícipe de lo social.

\section{Bibliografía}

Agamben, Giorgio (2005). Estado de Excepción. Homo Sacer II. Adriana Hidalgo Editora. Buenos Aires. Argentina.

Beck, Ulrich (1998). La sociedad del riesgo: Hacia una nueva modernidad. Cap. 3: "Más allá de las clases sociales". Barcelona, España. Paidós.

Dreyfus, Hubert y Rabinow, Paul (2001). Michel Foucault: más allá del estructuralismo y la hermenéutica. Ediciones Nueva Visión. Buenos Aires. Argentina.

Esposito, Roberto. (2005). Immunitas. Protección y negación de la vida. Amorrortu Editores. Buenos Aires. Argentina.

abierto re-significaciones e intervenciones. Cuando el territorio moderno, y toda su institucionalidad socializadora, se desmorona, pareciera que es el cuerpo uno de los nuevos territorios a ocupar. 
Cuerpo, poder y resistencia. (Para el archivo de las actuales políticas de control social) Iván Pincheira Torres

Fernández Buey, Francisco \& Riechman, Jorge (1994). “Redes que dan libertad". Paidós. Barcelona. España.

Foucault, Michel (1976). Undécima Lección en el Collage de France. Del poder de soberanía al poder sobre la vida. En la web en: http:/ / foucault.pais-global.com.ar/

(1989). Vigilar y Castigar. Nacimiento de la prisión. Siglo Veintiuno Editores. Ciudad de México. México.

(1992). Microfísica del Poder. Ediciones de la piqueta. Madrid. España.

Hardt, Michael; Negri, Antonio (2002) Imperio. Paidós. Argentina.

Illanes, María Angélica (2003). Chile Des-centrado. Formación socio-cultural republicana y transición capitalista (1810-1910). LOM Ediciones. Santiago. Chile.

Laqueur, Thomas (1994). La construcción del sexo. Cuerpo y género desde los griegos hasta Freud. Ediciones Cátedra. Madrid. España.

Le Bretón, David (2002). La Sociología del cuerpo. Ediciones Nueva Visión. Argentina.

Nievas, Flavian (1999). El control social de los cuerpos. Editorial Universitaria de Buenos Aires. Argentina.

Programa de Naciones Unidas para el Desarrollo (1998). Informe de Desarrollo Humano en Chile: las paradojas de la modernización. PNUD. Santiago.

Ramos, Marcela; Guzmán, Juan Andrés (2000). La guerra y la paz ciudadana. M. Ramos. Juan A. Guzmán. Lom Ediciones. Santiago. Chile.

Salazar, Gabriel (2002). La Nueva Historia y los Nuevos Movimientos Sociales. En Revista Chilena de Temas Sociológicos. Universidad Cardenal Raúl Silva Henríquez. Santiago, Chile.

(2002). Memoria histórica y capital social. CEPAL. Serie Políticas Públicas. No 55. Santiago. Chile.

(1990). Violencia política popular en las 'Grandes Alamedas'. Editorial Sur. Santiago. Chile.

Turner, Bryan (1989). El cuerpo y la sociedad. Exploraciones en teoría social. Fondo de Cultura Económica. Ciudad de México. México. 